\title{
Implementation of the E uropean Monetary Union and Its Sustainability, 1999-2002: Recommendations from a Dynamic Game
}

\author{
Maria Sophia Aguirre \\ The Catholic University of America
}

\begin{abstract}
This paper presents a dynamic theoretic model of monetary union break downs that result from violations of the macroeconomic targets agreed upon at the time of monetary integration. N on-cooperati ve behavi or of two constituen cies or interest groups results in multiple possible equilibria. The paper ana lyzes the conditions of financing and the cost of maintaining the targets that will determine whether or not a monetary union member will be subject to for eign reserves depletion or, in the extreme, an exchange rate attack. In addition, it provides the decision rule for European countries to determine if they should continue to participate in the monetary union or withdraw from it. Therefore, it indirectly provides an intuition for the conditions required for the monetary union to succeed. (JEL Classifications: F 31) 《Key Words: European M onetary Union, EU, Economic integration, Exchange rate sustainability.>
\end{abstract}

\footnotetext{
* Correspondence Address: Dept. of B usiness and E conomics, The Catholic University of America, Washington.D.C. 20064, U.S.A. (Tel) 1-202-319-5236, (E-mail). Aguirre@CUA.edu

(C2000 - Center for International Economics, Sejong Institution. All rights reserved.
} 


\section{Introduction}

As the date for the completion of monetary unification in the European Union approaches and the country members that meet the convergence criteria ${ }^{1}$ defined by the $M$ aastricht $T$ reaty were selected, questions concerning the social costs of such convergence and the sustainability of this system came into focus once again. All EU countries, with the exception of Sweden, Denmark, the United Kingdom, and Greece, fixed their exchange rates on the first day of 1999 in preparation for the adoption of a common currency, the Euro, in 2002. Once incorporated into the monetary union, nations will face penalties and fines if their budget deficits grow beyond target levels ${ }^{2}$. In theory, with a "no bailout" pledge from members, countries might even go bankrupt if their local economies fall into a recession or the reserves are depleted while the European Central Bank keeps money tight. The recessionary side effect that complying with the $M$ aastricht criteria has had and will continue having on EU members has generated "distributional conflicts", raising important economic, social, and political issues related to this matter. The high level of unemployment and large number of protected industries and agricultural products, coupled with a socialized economic structure, such as those of F rance, Spain, Italy, the UK, and the Nordic countries, have led these countries to achieve some of the criteria by means of heavy borrowing (today, average borrowing for the $E U$ is $80 \%$ of the $\mathrm{GDP}^{3}{ }^{3}$ ) and recession. In addition to this, the political cost of not meeting the

1. The criteria was tested against 1997 figures available in the spring of 1998 and are as follows: Inflation no more than $1.5 \%$ points above the average of the three best-performing states; long-term interest rates no more than two points above the average of the three best-performing states; budget deficit of 3\%or less of the GDP; public debt no more than $60 \%$ of the GDP; and exchange rates above the "normal margins" of the exchange rate mechanism (ERM) for two years. (Ref. Art. 109.J of M aastricht Treaty)

2. According to the German formula, governments that fail to keep their budget deficits below 3\%of the GDP would have to place a deposit with the European authorities. If the excess borrowing continued, the funds would be forfeited. Fines may be calculated at the rate of $0.2 \%$ of the GDP plus another $0.1 \%$ for every percentage point by which the deficit exceeded $3 \%$ of the GDP. This penalty could reach enormous amounts.

3. Calculated based on EUROSTAT and OECD information. 
social benefits requested by labor was very high, especially in the 1998 elections 4 .

This paper attempts to explain by means of an individual optimizing problem the effects that financing social benefits with debt or tax revenues to cover the negative distributional effects of monetary unification might have on the future of the EM U, especially between 1999 and 2002. It also seeks to determine the conditions that are required to smooth this transition. One source of concern is that, without monetary policy available for individual countries since first day of 1999, fiscal policy has to carry a greater share of the burden of potential recessionary effects during the adjustment period than it has thus far. In order to carry this burden, country members have to borrow or increase tax revenues. Borrowing, at a lower risk than before, is now possible within the euro capital market, thus raising the temptation to borrow too much which, in turn, could raise interest rates in EMU countries. Another concern is that countries might overborrow to such an extent that the market would fear a default. This would create instability in the market and, thus, a run on the euro.

Even if the issues mentioned above do not occur, cyclical and structural differences among EU economies remain, and their interest rates operate in different ways. There is little or no labor mobility among member countries, and wages are very rigid. M oreover, there is little room for an expansion of the EU budget to allow for big transfers since countries are under pressure to cut public spending to meet the Stability and Growth Pact. Thus, traditional sources of revenues become an attractive alternative, although this alternative jeopardizes a country's competitiveness as well as inflicts some welfare losses. If these transfers are not financed by increasing taxes, it will need to be financed by more debt, inflation tax and/ or devaluation, both of which are additional sources of inflation. Inflation tax and devaluation are not viable alternatives for these countries after 1999. Yet, it is also known that today's debt increase could lead to higher taxes and/ or inflation tomorrow. Therefore, economic agents could fear that countries will cover today's high public debt by higher taxation or monetarization, therefore undermin-

4. Giavazzi and Pagano [1990] suggest that political-economy considerations play a key role in the process that follows the establishment of the nominal anchor. 
ing the EMU's sustainability. In this case, economic agents will substitute domestic assets with foreign assets which they judge to offer protection from higher taxes or to be more solvent, while demanding higher benefits from their governments to compensate for high levels of unemployment and other recessionary effects.

Thus, after the EM U is in place, Europe's single currency design remains vulnerable between 1999 and 2002. Although the exchange rates had been fixed at the pre-announced parities in J anuary of 1999, national currencies will stay in circulation until the euro replaces them in 2002. If they retain market confidence, speculation could help the exchange rate reach the announced level. If not, fixed exchange rates could be attacked as happened during 1992-1993 with similar results ${ }^{5}$. Any lack of credibility in the market on the part of member countries or European authorities in their commitment to the EMU would give the market an incentive to test the system to its eventual destruction. It is relevant, therefore, to study the conditions under which credibility can be maintained or speculative activity prevented.

The equilibrium conditions derived in this paper suggest the type of structural reform necessary to make the transitional period between 1999 and 2002 successful and permanently support the EM U. In order to settle distributional conflicts in a permanent manner, reforms must take place either by changing the payoffs of the game or by inducing more cooperative play. This might demand deep institutional reforms in the case of European countries. Institutional reforms that provide some degree of fiscal flexibility for each country or decrease the burden on the fiscal deficit by privatizing some of the socialized benefits, as well as other changes that make a transitory redistribution of income easier, could facilitate the sustainability of a monetary union.

The remainder of the paper is organized as follows. Section II provides

5. Given the fixed exchange rate, countries will have to maintain the credibility of the fixed exchange rate level so as to avoid a speculative attack. For a more detailed analysis of the issue of credibility see Drazen and M asson [1994], Lindberg, Svensson, and Söderlind [ 1991], Garber and Svensson [1995], and Obstfeld [1996]. Some recent studies on speculative attacks include Werner [1992], deGrauwe [1994], Vegh [1995], Reeves [1997], and Velasco [1996]. 
the theoretical framework. Section III describes the equilibrium model. Section IV describes the conditions necessary for the existence of stable and oscillating devaluations. Section $V$ analyzes the robustness of the results of changes in the structure of the economy that better accommodate the EU reality. The paper ends with the conclusions and a discussion of possible interpretations of the model.

\section{Theoretical Background}

Departing from the model of policy reversal proposed by Vegh [1991] and M ondino, Sturzenegger, and Tommasi [1996], this model includes an economy consisting of agents who organize into pressure groups in order to request benefits from the governments. The groups' wealth is affected positively by the granting of the pressure groups' requests and negatively by their refusal. The additional expenditures incurred by the benefits requested by the pressure groups lead to a greater budget deficit unless financed by additional funding. Since inflation financing ends when the exchange rate is fixed, and the fiscal measures that would require these countries to balance their budget would lead to more recession, the remaining fiscal deficit must be financed either by issuing public debt or by raising local taxes. The crowding out effect of such borrowing will eventually increase nominal interest rates, which, in turn, causes real money demand and, thus reserves, to fall over time. This situation creates the expectation that a balance of payment crisis could develop. Therefore, the behavior of the member states is determined by conflicts of interest, and, in the face of domestic political pressure, countries could be pressured to violate the targets set by the $M$ aastricht Treaty.

The stage-game between groups alternates between a prisoner's dilemma and coordinated games. The dynamics arise from the optional allocation of assets response of individuals. Agents keep their domestic assets (which include money and bonds) which are subject to taxation or seek costly alternatives (foreign assets) that release them from possible tax increases or devaluations. Using the definition of Sturzenegger [1997], we call these alternatives financial adaptation ( $F$ ). The state variable is the degree of financial adaptation. Agents hold foreign assets depending on the degree of 
past deficits, the level of government indebtedness, the cost of financial adaptation, the current and expected levels of taxes, or in the limit, the expected devaluations. When the government grants the pressure groups' requests for additional benefits, the funding required for them can be understood as creating pressure for future tax increases and eventually perhaps even devaluations of currency. Therefore, from now on, we will center on tax increases because it is the most relevant factor for the case under study ${ }^{6}$.

One equilibrium the model generates supposes that the economy is initially at a point where there are no expectations of tax increases, and, therefore, no expectations of increases in the cost of financial adaptation. Once interest groups have weighted the costs they know will follow, i.e., tax increases (due to increasing government borrowing that, eventually, needs to be paid by taxes, monetarization, or the loss of reserves), and financial adaptation costs forced upon the groups' members in the current and future periods, each interest group will demand concessions from the government in the form of benefits or transfers. Under some conditions, it will be optimal for each group to demand benefits, and this demand will create pressure for tax increases and, eventually, devaluations. In response to the resulting risk of countries being unable to support their pre-determined exchange rate level, given the targets set in 1999, the process of financial adaptation deepens over time. These effects cause groups to recalculate their optimal behavior intertemporaly. Eventually, demanding greater benefits is no longer optimal, and interest groups accept the cuts in benefits. These cuts decrease the fiscal deficit of the country, bringing it closer to $M$ aastricht's target values and, thus, release the pressure of tax increases and devaluations, which brings the economy back to its initial state ${ }^{7}$. At this new equilibrium, the groups demand an increase in benefits once again, and the game begins again.

6. Increases in debt, as will be shown later, also increase taxes because of the funds that eventually are needed to serve the additional debt.

7. The behavior delivered by this model is similar to the predictions from a "myopia" model. In this case, however, the "myopia" is derived endogenously from fully rational forward looking behavior (Fudenberg and Tirole [1991]). 
The equilibrium previously described captures the problems faced by a monetary union's member countries which, in order to meet the criteria set for the EMU, suffer high levels of recession and debt. The results are due to the presence of both conflict and common interests. The equilibrium strategy is state dependent, with cooperation occurring when the danger of large tax increases or the breakdown of the currency exists. The equilibrium is sub-optimal. Therefore, in order for an increase in welfare to take place, there must be an agreement on policy decisions that modify the rules of the game.

Vegh [1991] models policy reversals in which stabilization plans succeed in lowering inflation collapse. The assumption in this model is that stabilization programs can be achieved easily by fixing the exchange rate. Supporting the exchange rate, however, requires the reduction of government deficits. As this takes place, two groups struggle over paying the costs of the tax package, and this struggle leads to a balance of payment attack. The decision process in this model is conceived as a war-of attrition with incomplete information. Mondino et al [1996] analyze the dynamics of inflation that arise from fiscal deficit caused by the non-cooperative behavior of interest groups. The decision process in their paper alternates between a prisoner's dilemma and a coordinated game. They find fully rational cycles of inflation which support the experience of Latin America. Person and Tabellini [1996], by using a model that combines credibility and policy coordination in monetary policy, suggest that a system of mandatory inflation, instead of the adoption of an intermediate money target, is a better approach to achieve monetary unification in a single market. Finally, Dewatripont and Roland [1995], using a model with aggregated and individual uncertainty concerning the outcome of reforms, suggest that a gradualist approach in implementing a reform, such as the one used in the EU, is easier to introduce, and it generates a higher investment response because of the lower option value of waiting than a big-bang approach would.

The models referred to above assume asymmetric information over the pay-off of the other party. This asymmetry is eliminated once the information is revealed, and further instability is not viable. In this paper, the model employed avoids this assumption and incorporates the possibility of inaction, delays, and policy reversals as larger levels of debt and/ or tax increas- 
es are incurred and constituencies interact. It follows M ondino et al [1996] in the sense that the stage-game also alternates between a prisoners' dilemma and a coordination game, but this paper is different in the sense that it allows for debt and tax financing while no inflationary elements are incorporated. The financing scheme for government expenditures is borrowed from Vegh [1991] but it differs from his approach in that no war of attrition or seigniorage is incorporated in this paper's model.

\section{The Equilibrium Model}

The model is an economy with a continuum of identical infinitely lived agents, except for a characteristic that is indexed by $i \in[0,1]$ which characterizes them in the collective action. They are organized in two politically active groups, $A=[0,1 / 2]$ and $B=[1 / 2,1]$. In this case, we take agricultureindustry, but any other dimension can be examined. Each period, agents receive, in addition to an endowment (e), a benefit $B_{t}$ from the government which they can demand and which is initially financed by debt, but that leads agents to expect an increase in taxes and, eventually, a weakening of the cur rency or even a devaluation. Agents decide on their level of financial adaptation based on the benefits they receive and their expectations of tax increases.

At the initial steady sate equilibrium when the exchange rate is fixed against the euro, government expenditures and the service of the debt are assumed to be financed by conventional taxes and seigniorage. At this time, there is some incomplete adjustment of tax revenue and, therefore, service of the public debt must be financed through debt accumulation until additional increases in taxes are implemented. Formally, this paper assumes that real tax revenues, at the time of fixing the exchange rate, $\tau_{\mathrm{t}-1-1}$, are given by

$$
{ }_{t-1}=g+d_{t-1}-\left[\mathbf{m}\left(\mathbf{\square}_{-1}\right)\right]
$$

where $g$ is the constant stream of government expenditures which are exogenously determined, $\rho$ is the constant and exogenous interest rate, $d_{t}$ is the outstanding public debt level, $\mathbf{m}\left(\boldsymbol{\square}_{\mathrm{t}-1}\right)$-for $\mathrm{m}(\cdot)$ representing the demand for money-denotes seigniorage, and $\eta$ is the fraction of seigniorage which is covered by initial increase in taxes (Therefore if $\eta=1$, there is no initial fis- 
cal adjustment). Thus, the required increase in taxes at time $t$, if benefits requested by the groups are conceded, is given by

$$
R_{t}=\left(d_{t}-d_{t-1}\right)+R(0)
$$

where $d_{t}$ is the public debt at time $t,\left(d_{t}-d_{t-1}\right)$ is the increase in the public debt, and $R_{t}$ is the required increase in taxes and increases with the rate of accumulation of public debt, and $R(0)=\eta\left[\boldsymbol{m}\left(\boldsymbol{\square}_{\mathrm{t}-1}\right)\right]>0$ before the fixing of the exchange rate.

The budget constraint for the government is:

$$
g_{t}+d_{t}=R_{t}\left(e-F_{t}\right)+(1-)\left[\mathbf{\square} m\left(\mathbf{n}_{-1}\right)\right]+\left(d_{t}-d_{t-1}\right)
$$

Thus, the government faces a constant stream of expenditures which are financed via regular taxation, debt, or seigniorage. Any additional expenses must be financed via more borrowing, which eventually requires tax increases and/ or the reduction of reserves, therefore undermining the predetermined exchange rate. For the sake of simplification, we assume that no seigniorage can be obtained once the exchange rates are fixed against the euro, and that monetary policy is relegated to the European Central Bank, i.e., we assume $\eta=0$. Therefore, the only source of revenue left is to increase taxation. After substituting the government budget constraint, the equilibrium in the assets market gives:

$$
\frac{1}{2}\left[B_{t}^{A}+B_{t}^{B}\right]+d_{t}=R_{t}\left(e-F_{t}\right)+\left(d_{t}-d_{t-1}\right)
$$

where $\left(B_{t}^{A}+B_{t}^{B}\right)$ are the benefits provided by the government to group $A$ and $B$ respectively, the unitary measure of the agents implies that the aggregate endowment equals individual endowments, $R_{t}\left(e-F_{t}\right)$ is the "wealth tax", and $F_{t}=\int_{0}^{1} f(i) d i . f$ denotes the individual and $\mathrm{F}$ the aggregate degree of financial adaptation. The welfare losses associated with the tax increase $\left(\phi\left(R_{t}\right)\right)$ are assumed monotonically increasing, $\phi(0)=0$, which has a convex shape.

The agents can hold an amount $\mathrm{f}_{\mathrm{t}}$ of their endowments in foreign assets, but at no time does each agent hold only foreign assets because of the large cost included for complete substitution of domestic currency ${ }^{8}$. Therefore, any tax increase affects part of the agents' holdings. The process of chang- 
ing $\mathrm{f}_{\mathrm{t}}$ is costly. For the sake of simplicity, it is assumed that an agent can freely increase the size of $f$ by a pre-specified amount $J$ in each period. The cost of exceeding $J$ is assumed infinite, but downward adjustments in the level of financial adaptation are free ${ }^{9}$.

In each period, the sequence of events starts when benefits are requested and announced. Afterwards, individuals act upon that information and decide on the optimal adjustment of their level of financial adaptation $\mathrm{f}_{t}$ based on their expectations of devaluation. Finally, pressure for tax increases results from this process.

The individual has a stage utility that depends linearly on consumption, $U(C)=c$. Because this economy is an endowment economy where all agents are homogenous, savings are zero. That is, no individual debt is allowed. This implies that agents will hold their endowment in domestic or foreign assets.

The individual choice variable is the degree of financial adaptation. B enefits are chosen strategically at the group level. Formally, the representative agent's problem is to maximize

$$
\sum_{t=0}^{\infty}{ }^{t} U_{t}
$$

by choice of $\left\{f_{t}\right\}_{t=0}^{\infty}$, for given sequences $\left\{R_{t}\right\}_{t=0}^{\infty}$, and subject to:

$$
\begin{aligned}
& f_{t+1} \in\left\{0, J, 2 J, \ldots, f_{t}, \min \left[f_{t}+J, e\right]\right\} \\
& c_{t}=e+b_{t}-R_{t}\left(e-f_{t}\right)-T_{t}-\left(R_{t}\right)
\end{aligned}
$$

where (5) is the utility function and $\delta$ is the discount factor, (6) is the mathematical representation of the law of motion, and (7) is the agent's budget

8. The cost could increase for many reasons. Examples include the inconvenience of dealing with foreign currencies, the obstacle of gathering information on foreign assets, etc. This is:

$$
T\left(f_{t}\right)= \begin{cases}t f_{t} & \forall f_{t}<e \\ t f_{t}+K & \forall f_{t}=e\end{cases}
$$

9. M ore general specifications generate similar results. M ondino et al [1993] show how a symmetric cost of adjustment function gives the same result as the stark version of the adjustment cost model that is also assumed in this paper. 
constraint where the three first terms represent the disposable income, $b_{t}$ is the benefit received, $T_{t}$ is the cost of holding foreign assets, and $\phi\left(R_{t}\right)$ is the welfare loss of a tax.

For the sake of simplicity, it is assumed that the political structure is such that individuals can obtain benefits only through group pressure, and their decisions can be reached by any voting mechanism since there is always group unanimity. A discrete action space is also assumed. Therefore, the group action set is $\{B, 0\}$ each period, i.e., they either request a transfer $B$ from the government or they do not. They choose strategies that maximize (6) for their representative agent. The stage pay-offs are dependent upon past actions through financial adaptation and, hence, expectations of tax increases. Therefore the game between groups can be seen as a dynamic game. To eliminate possible multiple equilibria, the equilibrium concept is restricted to a M arkov Perfection proposed in Fudenberg and Tirole [1991]. In this case, the equilibrium is a profile of state-space strategies that yields a $\mathrm{N}$ ash equilibrium in every proper sub-game. The state-space strategies are such that, at each node, the past influences the cur rent play only through its effect on a state vector which summarizes the direct effect of past information on the current environment.

\section{Equilibrium Strategies}

The equilibrium in this economy is a set of sequences $\left\{R_{t}, B_{t}^{A}, B_{t}^{B}, F_{t}\right\}_{t=0}^{\infty}$ such that:

(i) Given a $\left\{R_{t}\right\}_{t=0}^{\infty}$ sequence, $\left\{f_{t}\right\}_{t=0}^{\infty}=\left\{F_{t}\right\}_{t=0}^{\infty}$ maximizes the individual's problem for (5) and (6).

(ii) The sequences $\left(B_{t}^{A}+B_{t}^{B}\right)_{t=0}^{\infty}$ constitute a $M$ arkov Perfect equilibrium, i.e., each group chooses $t_{t}^{i}$ to maximize $U\left(b_{t}^{i}, R_{t}\right)+V\left(R_{t}\right)$ subject to:

a. $R_{t-1}$ given.

b. The dynamic equation for a tax rate increases if the aggregate financial adaptation (6) and the budget constraint of the government (4) are satisfied.

c. Player i follows strategy $b_{t}^{-i}$. 
To solve the equilibrium strategies, the following chain of events is followed. Since, at the start of fixing of the exchange rate, the fiscal situation is not consolidated, an agreement needs to be reached over a policy package which includes the distribution of the additional taxes required for the longrun sustainability of the EM S. Given the timing of the game and the type of equilibrium adopted, a sequence of demands for benefits is postulated. Individual agents, using the information received, decide on their demand for foreign currency $\left\{f_{t}\right\}$. To make their decision, they form expectations regarding the path of future tax increases, which, in turn, requires forming expectations on the aggregate level of financial adaptation ( $F)$, as both benefits and the excess borrowing determine the tax rate through equation (4). Then an asset equilibrium is found for which $F_{t}=f_{t}$. Once the assets' equilibrium is found, the path of benefits initially postulated is tested to see if it is optimal for both groups, conditional on the assets' equilibrium chosen, i.e., the equilibrium should be such that no deviations are profitable. In computing the profitability of deviations, assets' equilibrium along deviations from the equilibrium must be verified ${ }^{10}$.

Following M ondino et al [1996], $\mathrm{W} *\left(\mathrm{R}_{\mathrm{t}-\mathrm{l}}\right)$ is defined as the value function; in this case, for a group member in an economy that has experienced a tax rate increase equal to $R_{t-1}$ last period. $V *\left(R_{t-1}\right)$ is defined as:

$$
V^{*}\left(R_{t-1}\right)=W^{*}\left(R_{t-1}\right)-\frac{e}{1-}
$$

where e/ $(1-\delta)$ is the present discounted value of the endowment, and $V^{*}(\cdot)$ is the value function for the difference between the equilibrium path and the constant zero devaluation financial adaptation path.

In any Strong Symmetric M arkov Perfect Equilibria, the two groups will choose the same strategy ${ }^{11}$. Therefore, equation (1) and the fact that there is a unit mass of agents can only produce the following set of tax rate increases: $0, B / e, B /(e-J)$, and B/ $(e-2 J)^{12}$.

Four possible steady-state devaluation configurations can be found:

10. N otice that as groups maximize the utility of a representative agent, each group internalizes the tax increase paid by its members, but not the cost imposed on the other groups.

11. Notice, however, that actions will not be constant over time in some of the equilibria. 
1. No tax increases: $R_{t}=0 \forall t$. This occurs when the costs of a tax increase is high. In this case, groups do not find it profitable to induce devaluations by demanding benefits.

2. Steady tax increases: $R_{t}=B$ / $e \forall t$. This equilibrium is likely to result if $T_{t}$ is high and the welfare cost of a tax increases is low.

3. Small tax increases cycles: $R_{t}=0, B /(e-J)$. These will take place when the cost of a tax increase is low and the costs of financial adaptation are moderate. The low cost will induce groups to demand benefits, while the moderate costs will induce agents to an intermediate pattern of financial adaptation which translates into small tax increases cycles.

4. Large tax increases cycles: $R_{t}=0, B /(e-2 J)$. This also requires low costs of tax increases. These equilibria are possible for a wider range of financial adaptation costs than those possible for the small tax increases cycles. Low costs induce large levels of financial adaptation which generate large tax increases, but the large costs can also sustain a massive financial adaptation as equilibrium tax rate increases are high.

In the propositions below, conditions under which zero and steady tax rate increases equilibria exist are characterized. They show whether or not there will be tax rate increases and the reason that high constant large tax rate increases are not possible. The case analyzed is one in which $e \in(2 J, 3 J)$ so that the financial technology reduces to $f \in\{0\}, 2,], e\}^{13}$.

Proposition 1: A steady zero tax rate increase is an equilibrium iff:

(i) $<\mathrm{B} / 2(e-J)$ and $\mathrm{B} / \mathrm{z} J+\mathrm{B} / 2(e-J)$

Proof: $R_{t}=0 \forall t$ requires that $\left\{b_{t}\right\}=\{0,0\}$ and $\left\{F_{t}\right\}=\{0,0\}$. This implies that

12. $N$ otice that as $F \rightarrow e, R \rightarrow \infty$, and that the conditions on the cost of tax rate increases function will prevent the economy from ever reaching that point; the threat of depleting reserves that would lead to a strong speculative attack and the consequent breakdown of the EM $U$ is enough to induce unilateral restraint in the demand for benefits. Another way to explain this behavior is that $R^{\prime}>0$ implies that at some point in $t$, the government may simply run into insolvency. Therefore, further increases in $R$ are infeasible.

13. This will restrict the cycles to be two-period phased when they exist. 
the demand for benefits will be zero at all times, and that no financial innovation will take place to avoid unnecessary costs of operating in foreign assets markets. In order to evaluate the profitability of deviations to $b_{i}=B$, the off-equilibrium monetary behavior is specified. For $\xi<B / 2 \mathrm{e}$, the only consistent monetary behavior is $\mathrm{f}=\mathrm{F}=\mathrm{J}$. For $\xi>\mathrm{B} / 2(\mathrm{e}-\mathrm{J})$, the consistent behavior is $\mathrm{f}=\mathrm{F}=0$. For the intermediate values, both assets (monetary) equilibria are self-fulfilling. In that case, $f=F=f$ is considered since it induces a zero tax increase equilibrium for the larger set of parameter values. The next step is to verify the conditions for profitable deviations for the two cases of $\xi$ smaller and greater than B / $2(\mathrm{e}-\mathrm{J})$.

(a) When $\xi<B / 2(e-J)$, an aggregate level of financial adaptation of $F=J$ induces $f=F=$, since $\zeta<R=B / 2(e-J)$, the cost of holding foreign assets is smaller than the tax rate increase. The value function of a deviation, given that the tax increase was zero in the last period and will be zero again next period, is:

$$
V^{D}(0)=B-R_{t}(e-J)-J-\left(R_{t}\right)+V^{*}(0)
$$

The terms include the gains from the transfer $B$ minus the tax rate increase $\left(R_{t}(e-J)\right)$, the transaction cost due to some financial adaptation $(\xi))$, and the cost of the tax rate increase $\left(\phi\left(R_{t}\right)\right)$. Finally, the last term represents the discount value of continuing along the optimal zero tax rate increase strategy. This last term is 0 .

Equation (1) implies that $R_{t}=B / 2(e-J)$ so that the above equation reduces to:

$$
V^{b}(0)=\frac{B}{2}-J-\left(\frac{B}{2(e-J)}\right)
$$

Since $V *(0)=0$, for the deviations to be profitable, it is necessary that $V^{b}(0)>0$, which results in $B / 2>\zeta J+\phi B / 2(e-J)$, so the zero-inflation will be an equilibrium when $\xi$ is low, iff $B / 2<\xi J+\phi B / 2(e-\jmath)$.

(b) When $\xi \tau \gg B / 2(e-J)$, then $f=0$. In this case, the gains from deviating from the postulated equilibrium are $\mathrm{V}^{\mathrm{b}}(0)=\mathrm{B} / 2-\phi(\mathrm{B} / 2 \mathrm{e})$. Once again, since $V^{*}(0)=0$, a deviation is unprofitable when $\phi$ is high as long as $e<\phi$. Q.E.D. 
Proposition 2 : A steady tax rate increase will be an equilibrium iff:

(i) $>B / e$ and $B / \triangleright[(B / e)-(B / 2 e)]$

Corollary: A large steady tax rate increase cannot occur in equilibrium.

Proof: $R_{t}=B / 2 \forall t$ implies that $\left\{b_{t}\right\}=\{B, B\}$ and $\left\{F_{t}\right\}=\{0,0\}$. From equation (4), if a tax increase takes place, then in an equilibrium, both groups demand benefits, and tax increases must be greater or equal to $B /$ e. Hence, if $\zeta<B / e$, the savings in tax increases are always larger than the costs of transactions in foreign currency so that it is always optimal to adapt financially. In steady state, they will operate at $F=f \rightarrow e . f=F=0 \forall t$ requires, on the other hand, $\zeta>B /$ e. Otherwise, financial adaptation would be optimal for each agent ${ }^{14}$. The value for agents, which is denoted by $v$, is: $v(f)=-\zeta f+R f$. Assets equilibrium will either take place at $F=f=e$ if $\zeta<B /$ e or at $F=f=0$ if $\zeta>B$ / e. The value of the optimal strategy equilibrium path is:

$$
V^{*}(R)=-F-\frac{B}{e-F}+V^{*}(R)
$$

In this case, benefits cancel with the tax rate increases. The value of deviating to $b=0$ is:

$$
V^{0}(R)=-\frac{B}{2}-F-\left(\frac{B}{2(e-F)}\right)+V^{*}(R)
$$

so that:

$$
V^{*}(R)-V^{0}(R)=\frac{B}{2}+\left[\frac{B}{2(e-F)}-\frac{B}{e-F}\right]
$$

Since the increased tax rate that results when both parties demand benefits is always twice as high as when only one party makes demands, the term in brackets is always negative and decreasing in the degree of financial adaptation. Hence, it is optimal to deviate from constant and large tax rate increases whenever $V^{*}(R)-V^{0}(R)<0$, or:

14. N otice that this is the least restrictive structure under which this assets equilibrium could exist and where tax rate increases are constant. 


$$
\frac{B}{2}<\left[\left(\frac{B}{e-F}\right)-\left(\frac{B}{2(e-F)}\right)\right]
$$

When $\mathrm{F}=0$ equilibria exist, equilibria have constant small tax rate increases $(R=B / e)$ as the second condition of ( $i)$ demands. In other words, it is not profitable to deviate as long as B / $2>\phi(B / e)-\phi(B / 2 e)$. F or F $\rightarrow e$, an alternative assets equilibrium without increases in asset holdings exists. Nevertheless, given the assumption of the shape of the cost of devaluations, deviations from the strategy will be profitable with large tax rate increases. This supports the intuition that the risk of a breakdown of the EMU is what eventu ally leads to demands for lower benefits. Q.E.D.

The two propositions provide important intuition because they suggest conditions under which zero or a steady tax rate increase exist. Zero devaluation requires the costs of tax rate increases to be high. For the case of the $E U$, one can conclude that this would occur if the size of the tax increase is such that it would significantly affect a country member's terms of trade or competitiveness, or if total wealth greatly decreases within the EU. Specifically, if this tax rate increase would lead E uropean investors to search for foreign assets holdings rather than domestic assets, thus avoiding the possibility of future taxation. If, instead, financial adaptation is cheap relative to tax rate increases, constant tax rate increases are not sustainable. In these cases, financial adaptation takes place, increasing the pressure to raise taxes unboundedly. As increases of tax rates accelerate, however, costs increase, and, eventually, because of the need to avoid a significant decrease in the tax base and/ or the depletion of reserves, stabilization of the exchange rate follows. Therefore, only constant small tax rate increases can be verified. This will result if the costs of operating in a financially adapted economy are high and the costs of tax rate increases are low. Otherwise, the groups would refrain from demanding benefits, and zero constant tax rate increases would result. Here, the benefit of not asking for additional benefits equals the discounted present value of additional taxes $\left(R_{t} / \rho\right)$

Finally, if the costs of tax rate increases do not increase quickly, and the cost of operating in foreign assets are low, there is no constant tax rate increase equilibria. Because it is cheap to financially adapt, the savings from the tax rate increase almost always dominate the operational cost. The rela- 
tively low marginal cost of tax rate increase makes each constituency willing to tolerate tax rate increases. The result is that no constant tax rate increase program will survive in this economy. This suggests that if the transition from fixed exchange rate levels to the euro is to succeed, the default riskpremium must remain high so that both constituencies are not willing to tolerate policies that would put pressure on tax rate increases or more debt. That is, pressure groups will be willing to bear the recessionary effects without requesting any additional benefits because of the high cost that weakening the credibility of the country's currency and depleting central bank reserves would incur.

Figure 1 shows the possible combinations of $\zeta$ and $\phi$ that generate the different equilibria discussed above for $\zeta(R)=\alpha \zeta^{15}$. Constant tax rate increases result in the southeast region. Constant zero tax rate increases will occur for large tax rate increases costs. Finally, in the southwest region, no constant tax rate increases equilibria exists. The condition that rules out stable tax rate increases requires relatively small costs of operating in foreign currencies and low costs of tax rate increases. The first restriction eliminates the possibility of sustainable tax rate increases. The second induces groups to deviate from small tax rate increases.

\section{Figure 1}

\section{Equilibria with Steady Devaluation}

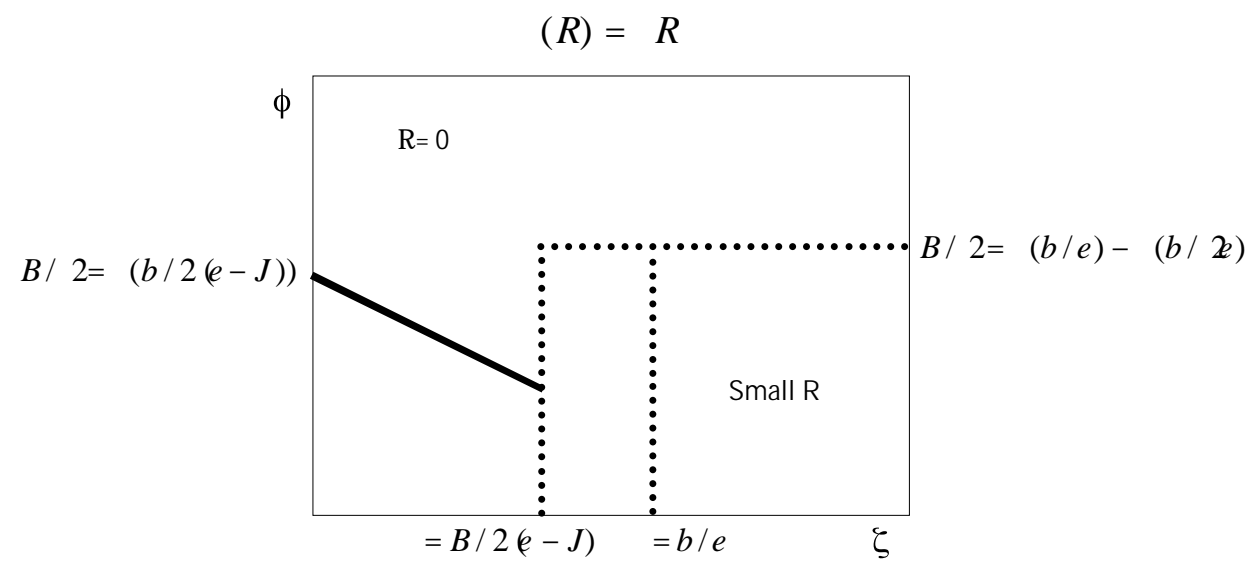

15. If $\phi(\cdot)$ were strictly concave or convex, a region of multiple steady tax rate increases equilibria or with no equilibria at all could be found. 
B efore defining the conditions to observe small and large devaluation cycles, the following definitions are needed: a small tax rate increases cycle is an oscillation from 0 to $B /(e-J)$, and a large tax rate increases cycle is from 0 to $B /(e-2 J)$. In addition, to observe cycles, it must be the case that the $M$ arkov Per fection strategy is:

$$
b_{t}^{i}= \begin{cases}0 & \forall R>\bar{R} \\ B & \forall R \leq \bar{R}\end{cases}
$$

Proposition 3: Small tax rate increases cycles constitute an equilibrium iff:

(i) $B / 2(e-J)<<B /(e-J)$

(ii) $B / \triangleright J+[B /(e-J)-(B / 2)]$ and $B / 2<2 J+(B / 2 \notin-2 J))$

$$
-(1-)\left(1-{ }^{2}\right)[J+(B /(e-J)]
$$

Proof: To observe small tax rate increases, it is necessar y that $F_{t}=\{0, j\}$. Because of assets consistency $f=F$, and, therefore, $f$ will also oscillate from 0 to J as long as:

$$
\begin{aligned}
& v(0, J)-v(0,0)=J(B /(e-J)-)>0 \text { and } \\
& v(0, J)-v(J, 2 J)=J+J(J+B /(e-J))>0
\end{aligned}
$$

or, equivalently, as long as condition (i) holds.

To cor roborate the optimality of the required strategy (9), which implies a sequence of benefits $\{0, B, 0, B \ldots\}$, the deviations from zero or some tax rate increase are tested. In this case:

$$
V^{*}(0)=-J-\left(\frac{B}{e-J}\right)+V^{*}(R)
$$

and

$$
V^{*}(R)=V^{*}(0)
$$

where $\mathrm{V}^{*}(0)$ is the value function along the equilibrium path when there is no tax rate increase at $t-1$, and $V *(R)$ is the value along the equilibrium path when a tax rate increase took place at $t-1$. Let $V^{b}(R)$ be the value of 
the function off the equilibrium path when the contingencies ask for a transfer when it is not optimal. This means that a tax rate increase takes place for one more period. Finally, let $\mathrm{V}^{0}(0)$ be the value off the equilibrium path when no benefits are demanded when they should be. A tax rate increase still takes place. After a one period deviation, the agents revert to playing equilibrium strategies. To evaluate $\mathrm{V}^{0}(0)$, the assets equilibrium of the agent is examined. Since the economy verified no tax rate increase and it moves along the equilibrium path, financial adaptation is zero. This means that the case can be restricted to $F=0$ or $\mathrm{J}$. If $\mathrm{F}=\mathrm{J}$, and $\mathrm{f}$ can only assume the values 0 or $\mathrm{J}$, then the condition for it to be an asset equilibrium is $\zeta<B / 2(e-$ 2)), which violates (9). If $F=0$, then the condition for monetary equilibrium is $v(f=0)>v(f=J) \Rightarrow \zeta>B / 2 e$, which satisfies (9). The resulting low tax rate increase from the deviation does not justify the costs of the financial response. Therefore:

$$
V^{0}(0)=-\frac{B}{2}-\frac{B}{2 e}+V^{*}(R)
$$

The loss from deviating equals:

$$
V^{*}(0)-V^{0}(0)=-J+\left(\frac{B}{2 e}-\frac{B}{e-J}\right)+\frac{B}{2}
$$

which is always positive according to condition (ii) of the theorem.

For the case in which benefits are demanded when they should not be, the tax rate increase in $t-1(f=J)$ will allow agents to choose $f \in\{0, J, 2\}\}$. To cor roborate the assets equilibrium conditions, the values of $F$ are evaluated. If $F=2$ J, and $\zeta<B / 2(e-2 J)$, then 2 J is an equilibrium. No assets equilibria exists for $F=J^{16}$. Finally, if the costs of financial adaptation are sufficiently high, $F=0$ could also result in an equilibrium. If this is the case, then a fluctuating equilibria will not exist. Therefore, $F=f=2$ J equilibrium is examined. The value function in the case of a deviation is:

$$
V^{b}(R)=\frac{B}{2}-2 J-\left(\frac{B}{2(e-J)}\right)+V^{*}(R)
$$

16. Mondino et al[1993] find that there could be an equilibrium for an uninteresting knife case. 
Since tax rate increases take place in this period, the game restarts along the equilibrium path next period to a no tax rate increase stage $V *(R)$. For the deviation to be unprofitable, proposition (ii) should be verified. Q.E.D.

Equilibrium will exist when costs of operating in a financially adapted economy, $\zeta$, are large enough that it is preferable for agents to suffer the tax rate increase rather than to operate with alternatives. This implies that cycles of small tax rate increases can exist under certain conditions. The cost of transaction in foreign assets needs to be small enough to make it beneficial for the agents to request benefits in spite of causing future tax rate increases. However, this will encourage agents to reduce the demand for benefits in the following period while $\zeta$ needs to be high enough to induce groups to reduce the foreign assets holdings when there are small tax rate increases. This restriction is important because, in the absence of it, agents will prefer to hold foreign assets in anticipation of a future tax rate increase. Then assets equilibria would imply tighter fiscal policy, and any demand for benefits would lead to large tax rate increases.

There are two additional restrictions on the tax rate increase cost function. The tax rate increase cost cannot increase too quickly because, if it did, it would be optimal for the groups to unilaterally deviate and not demand benefits when the equilibrium strategy indicates positive demands. At the same time, when large tax rate increases exist, the cost of tax rate increases must be increasing rapidly so that groups do not find it optimal to demand benefits, accelerating tax rate increases, and thus violating the $M$ aastricht Treaty if a period of moderated tax rate increases exists. At the same time, the cost of tax rate increases does not increase rapidly enough, and, therefore, this failure leads to a breakdown of the system. Under the proposed structure during 1999-2002, one can expect that while it is feasible that an EMU member might satisfy these restrictions, it is more likely, given the present economic conditions of member countries, that this would not be the case.

F inally, to complete the fourth alternative, the conditions for large tax rate increases cycles are considered.

Proposition 4: An equilibrium with cycles of large tax rate increases oscillating from 0 to $B /(e-2)$ ) exists iff: 
(i) $<B / 2(e-2 J)$ and $B / \gg(B /(e-2 J)-B / 2 \notin-2 J))$

Proof: To observe large tax rate increases cycles $\{0, B /(e-2 J)\}$, it is necessary that benefits demand $\left\{b_{t}\right\}$ be $\{0, B\}$ and that the aggregate financial adaptation $\left\{F_{t}\right\}$ be $\left.\{, 2\}\right\}$. Once again, if tax rate increases have an oscillatory path, the optimal path for $f$ will too. To verify the conditions for the path of $F$ constituting an assets equilibrium (i.e., $f_{t} F_{t} \forall_{t}$ ), consider the following possible choices and the corresponding value of these paths ${ }^{17}$ :

$v(\{0, J\})=-J+J S /(e-2 J)$ and $v(\{e-2 J\})=-J-2 J+2 J B /(e-2 J)$

For $\{1,2\}\}$ to be an individual optimal strategy, it is necessary that $\zeta<B / 2(e-2)$ ), which is the requirement mentioned in proposition (i) and $\zeta>(B-K) /(e-J)$. In order to check the group $M$ arkov perfect equilibrium with cycles, it is necessary that the strategy have the form (9). In this case, the value function for the equilibrium path is:

$$
V^{0}(0)=-2 J-\left(\frac{B}{e-2 J}\right)+V^{*}(R)
$$

and

$$
V^{*}(R)=-J+V^{*}(0)
$$

For the case where $R_{t-1}=0$, strategy ( 9 ) requires $b=B$ resulting in a payof $f$ $V^{*}(0)=V^{0}(0)$. Given $\left.\zeta<[B / 2(e-2])\right]$, i.e., the transaction cost of financial adaptation is low, it is easy to verify that assets equilibrium along the deviation implies $F=f=2$. The deviation group value function is:

$$
V^{0}(0)=-\frac{B}{2}-2 J-\left(\frac{B}{2(e-2 J)}\right)+V^{*}(R)
$$

and, therefore, for the deviations to be unprofitable, requires $B / 2>\phi(B /(e-$ 2J) $-B / 2(e-2 J))$ which is proposed in (i).

The alternative deviation is to demand benefits when the adjustment to $M$ aastricht is taking place. Because the cost of transaction in foreign assets

17. $\{\mathrm{s}, \mathrm{e}\}$ does not need to be considered because a large $\mathrm{K}$ is assumed. 
is low and financial adaptation at $\mathrm{t}-1$ is at $2 \mathrm{~J}$, individuals move to $\mathrm{f}=\mathrm{F}=\mathrm{e}$. This leads first to a depletion of foreign reserves and eventually, to a break down of the currency, making deviations unprofitable for the group. Q.E.D.

Proposition four shows that large tax rate increases cycles are feasible for low transaction and tax rate increases costs. A high transaction cost $(\xi)$ would imply that holding a large $f$ is not individually optimal. Assets equilibrium would result in lower average tax rate increases than those of proposition 3. Therefore, low $\xi$ are necessary for this equilibrium to exist. The second equilibrium condition requires that the cost of tax rate increases does not increase greatly at large levels of tax rate increases since this would provide the incentive to demand benefits even when groups know that this will result in large tax rate increases. At the same time, there are strong incentives to refrain from demanding benefits when there has been large tax rate increases because this will lead the economy to a depletion of foreign reserves and, eventually, an exchange rate breakdown. It is precisely this threat of breakdown, together with the cost of transactions that this implies, that ensures that groups find it optimal to accept the fiscal policy that the agreed upon fixed exchange rate requires. Yet, because the marginal cost of a tax rate increase is sufficiently low, once the targets are reached, it is optimal for the constituencies to again claim benefits. It would seem that this type of cycle is not applicable in the case of the EU, but, rather, it corresponds to the hyperinflationary episodes witnessed in Latin America throughout the 1980s when money was used as means of financing large government deficits.

In summary, propositions 3 and 4 have shown that a constant tax rate increase equilibrium may not result, and, thus, the economy will oscillate between tax rate increases periods and stable periods. The periods of stability will be associated with fiscal restraint and low monetary growth, both elements of the unification agenda. If stability can be sustained, this will have a positive welfare effect. However, the nature of interactions between the government and the private sector are such that this can not be achieved without substantive structural reforms. 


\section{Extensions}

This section considers two extensions that better capture the reality of the European M onetary System while testing the robustness of the results thus far presented. In particular, two variations of the model used are incorporated. First, the strong symmetric equilibrium is relaxed by incorporating a non-symmetric extension of proposition 1. Second, different degrees of financial adaptation are allowed.

For the first case, consider a steady tax rate increase equilibrium in which only group $A$ asks for benefits equal to $2 B$, while group $B$ does not demand any. In this case, the tax rate increase will be equal to $B /$ e and an optimal level of financial adaptation equal to zero is obtained by keeping the assumptions of proposition 1 .

Proof: To check if there are incentives for group B to ask for a transfer and for $A$ not to do so. In this case, the value function equals:

$$
\begin{aligned}
& V^{A^{*}}(0)=B-(B / e)+V^{A^{*}}(R) \\
& V^{B^{*}}(0)=B-(B / e)+V^{B^{*}}(R)
\end{aligned}
$$

Group B's deviation is not profitable as long as:

$$
V^{B 2 b^{*}}(0)-V^{B^{*}}(0)=(-2 B / e+B / e)+B<0
$$

For group A, a deviation is not profitable as long as:

$$
V^{A 0}(0)-V^{A^{*}}=-2 B+(B / e)
$$

Both cases assume $\xi$ is large enough for the assets equilibrium to remain with no financial adaptation.

The intuition for the equilibrium is that tax rate increases will be high in periods of benefit demands because individuals find it optimal to financially adapt. Restraint will follow at $t+1$ to avoid the depletion of reserves, and therefore of the system. Thus, the cost of financial adaptation does not seem to restrict the results previously obser ved.

For the second extension, i.e., the case where different degrees of financial adaptation are allowed, consider a more general case of the cost finan- 
cial adaptation function. In this case, individuals can choose whether to adapt from $f=0$ to $f=J$ and pay a cost of $2 \beta$ J. The proportionality of the cost function stresses the difference with the previous case. The seguence of the transfer demands are postulated to be $\{B, 0, B, 0, \ldots\}$ and the ag fregate financial adaptation to be $\{2\}, 0,2], 0 \ldots\}$. The conditions under wh $f=F$ and assets equilibrium exists can be determined. These conditions imply restrictions on the maximum size of the cost of financial adaptation, $\beta$, the cost of operating in a financially adapted economy, $\zeta$, and on B and e, the transfer size and the endowment. If an assets equilibrium exists, the necessary conditions for proposition (4) hold. That is, it is necessary that the transfer be greater than the increase in the cost of tax rate increases that will be caused by group $A$ when it does not deviate from equilibrium. Yet, because individuals do not find it optimal to adapt financially, tax rate increases will be large when benefits are demanded. The intuition for the equilibrium in this case is that since group B requests a benefit, group A will follow the same behavior. Once the threat of a tax rate increase is higher and more costly, one of the groups will avoid demanding benefits. In the former case, the cost of financial adaptation technology does not seem to represent a threat to the oscillating equilibria.

Proof: The cost function is assumed to be of the form $c(R F)=\beta R F$ or $\beta$ J and $\beta 2$, as was previously mentioned. The postulated sequence is $b=\{B, 0\}$ and $f=\{2\}, 0\}$. In this case, the multiple possible deviations from monetary equilibria are:
$v(2 J, J)-v(2 J, 0)=c(2 J)-c(J)-J<0$
$\forall>$
$v(J, 0)-v(2 J, 0)=+J-J R<0$
$\forall<R-/ J=B /(e-2 J)-J$
$v(e, J)-v(2 J, 0)=-J+B-K-(e-2 J)<0$
$\forall>(B-K) /(e-J)$
$v(e, 2 J)-v(2 J, 0)=-2 J+J+B-K-(e-2 J)<0 \forall>(J+B+K) / 2$

If all conditions are met, then the group payoffs along the equilibrium and off the equilibrium paths remain to be checked:

$$
\begin{aligned}
& V^{*}(0)=-2 J-\left(\frac{B}{e-2 J}\right)-2 J+V^{*}(R) \\
& V^{*}(R)=V^{*}(0)
\end{aligned}
$$


The conditions for local deviations to be profitable are:

$$
V^{*}(0)=V^{0}(0)=\frac{B}{2}-\left(\frac{B}{e-2 J}-\frac{B}{2(e-2 J)}\right)>0
$$

and $\xi<B / 2(e-2 J)-\beta / J$ for monetary equilibrium under this deviation. The second deviation is satisfied for certain when:

$$
V^{*}(R)-V^{B}()=-\frac{B}{2}+2 J+(\infty)-(\cdot)+V^{*}(0)-V^{*}(R)>0
$$

Q.E.D.

\section{Conclusions}

The aim of this paper was to clarify the conditions necessary for a successful transition to the EMU between 1999 and 2002. The use of tools previously developed in the literature to explain hyperinflationary episodes followed by stabilization plans has facilitated the determination of these conditions.

The program of fiscal restraint is offered to society as a means to sustain the fixed exchange rate level vis a vis the euro as proposed by $M$ aastricht, but such an arrangement will only be successful for a short time. While tax rate increases that are small or zero are welfare enhancing, pressure groups will find it in their best interest to request benefits, thus leading to pressure for tax rate increases. A zero tax rate increase will be the most likely outcome if the cost of a tax rate increase is high, i.e., if the cost of a tax rate increase is such that it would significantly affect a country's terms of trade or competitiveness within the EU or would encourage large capital flight. Constant small tax rate increases will result if the costs of operating in a financially adapted economy are high and the costs of tax rate increases are low. It is also shown that, for an oscillating tax rate increase to take place, it is necessary that tax rate increases are not very costly and that the cost of operating in a financially adapted system also be low. These cycles entail high welfare losses for society, losses that result from costs of tax rate increases, its variability, and the costs of operating in a financial system that 
is efficient as a tax rate increase hedge but less so as a resource allocator. Consequently, the results suggest that if the transition from a fixed exchange rate level to the euro is to be successful, the default risk-premium must be kept high enough so that pressure groups are not willing to tolerate policies that would put pressure on tax rate increases. Thus, the "no bailout" pledge is key.

Influential policy makers in Europe argue that the ECB should adopt an intermediate money target and that outside countries should be required to stabilize their exchange rates towards the euro. This would mean that these economies would have to destabilize their economies in order to absorb speculative attacks and other types of shocks. It is clear that the economic and political cost of such a proposal will be difficult for any government to sustain.

Therefore, in order for the exchange rate to survive, long-run adjustments are necessary. These are also suggested in this model. In order to permanently settle the distributional conflicts, structural reforms must either change payoffs of the game or somehow induce a more cooperative play. These adjustments may include increasing the cost of tax rate increases or the cost of operating in foreign assets. The last case is of interest because speculators could be tempted to attack one EM U member country by using another member country's currency. Thus, institutional reforms that provide some degree of fiscal flexibility to each country or decrease the burden on the fiscal deficit by privatizing some of the socialized benefits as well as other changes that make a transitory redistribution of income more difficult could facilitate the sustainability of a monetary union.

An alternative approach to achieve and sustain the EMU in a single market has been proposed by Person and Tabellini [1996], i.e., a system of mandatory inflation rather than the adoption of an intermediate money target. They suggest that, in this case, the burden of coordination will be shared more equally, and, therefore, it would make this regime much more politically viable. In addition, this system would facilitate monetary cohabitation in two ways. First, the negative effect of competitive devaluations will rule out these devaluations. Second, inflation targeting will restore domestic credibility, thus assuaging the fear that high public debt will eventually be monetarized. Furthermore, price stability reduces uncertainty about future 
inflation and leads to smaller nominal-exchange rate volatility.

A condition sine qua non for either system, however, is the implementation of some measure that would make the violation of these targets expensive. In the first case, the burden will fall on the government. In the second case, the burden of the penalty will fall on the central banks.

\section{References}

Avesani, R., G.M ., Gallo, and M. Salmon [1995], "On the Nature of Commitment in Flexible Target Zones and the M easurement of Credibility: The 1993 ERM Crisis," in C. Bordes, E. Girardin, and J. M elitz, (eds.), European Currency Crisis B efore and After, St. M artin's Press, New York; pp. 106-130.

DeGrauwe, P. [ 1994], "Incomplete M onetary Unions: The European M onetary System," in The Economics of M onetary Integration, 2nd ed., Oxford University Press, Oxford; pp. 95-145.

Dewatripont, M., and G. Roland [1995], "The Design of Reform Packages under Uncer tainty," American E conomic Review 85; pp. 1207-1223.

Drazen, A., and P.R. M asson [1994], "Credibility of Policies versus Credibility of Policy M akers," Quarterly Journal of E conomics 109; pp. 735-754.

Feldstein, M . [1982], "Government Deficits and Aggregate Demand," Jour nal of M onetar y E conomics 9; pp. 1-20.

Fudenberg, D. and J. Tirole [1991], Game Theory, M IT Press, Cambridge, $\mathrm{MA}$.

Garber, P. and L.E. Svensson [1995], "The Operation and Collapse of Fixed Exchange Rate Regimes," in G.M. Grossman and K. Rogoff, (eds.), Handbook of International Economics, Vol. 3, North-Holland, Amsterdam.

Giavazzi, F., and M. Pagano [1990], "Can Severe Fiscal Contractions Be Expansionary: Tales of Two Small European Countries," NBER Macroeconomics Annual.

Lindberg, H., L.E.O. Svennson and P. Söderlind [1991], "D evaluation Expectations: The Swedish Krona 1982-1991," NBER Working Paper No. 3918.

Makowski, L. and J.M . Ostroy [1995], "Appropriation and Efficiency: A Revi- 
sion of the First Theorem of Welfare Economics," J Jurnal of E conomic Literature 37; pp. 808-827.

M ondino, G., F. Sturzenegger, and M. Tommasi [1996], "Recurrent High Inflation and Stabilization: A Dynamic Game," International Economic Review 37; pp. 981-996.

Mondino, G., F. Sturzenegger and M. Tommasi [1993], "Recurrent HighInflation and Stabilization: A Dynamic Game," Working Paper N 0. 678 Department of Economics, UCLA.

Obstfeld, M. [1996], "M odels of Currency Crises with Self-fulfilling Features," European Economic Review 40; pp. 1037-1047.

Persson, T. and G. Tabellini, [1996], "M onetary Cohabitation in Europe,"

AEA Papers and Proceedings 86; pp. 111-116.

Reeves, S. [1997], "Partial Credibility and Policy Announcements: "The Problem of Time Inconsistency in M acroeconomics Revisited," Atlantic E conomic Journal 25; pp. 344-357.

Sturzenegger, F . [1997], "Understanding the Welfare Implications of Curren-

cy Substitution," Journal of Economic Dynamics and Control 21; pp. 391-416.

Svensson, L.E.O . [1992], "The F oreign Exchange Risk Premium in a Target Zone with Devaluation Risk," Journal of International Economics 33; pp. 21-40.

Tabellini, G. [1986], “M oney, Debt, and Deficits in a Dynamic Game," Jour nal of E conomic Dynamics and Control 10; pp. 427-442.

Vegh, C. [1991], "Losing Credibility: The Stabilization Blues," M imeo, International M onetary Fund.

Vegh, C. [1995], “N ominal Interest Rates, Consumption Booms, and Lack of Credibility: A Quantitative Examination," Journal of Development Eco nomics 46; pp. 357-378.

Velasco, A. [1996], "Fixed Exchange Rates: Credibility, Flexibility and M ultiplicity," European Economic Review 40; pp. 1023-1035.

Werner, A. [1992], "Time-varying Devaluation Risk, Interest Rate Differentials, and Exchange Rates in Target Zones: Empirical Evidence from the EMS," Memo \#1993-11, Okonomisk Institut, Aarhus Universitet, Denmark. 